Biophysik 7, 358 (1971)

(C) by Springer-Verlag 1971

\title{
Corrigenda
}

\section{On the Stability of the Kinetics of a Certain Class of Biomolecular Reactions}

\author{
Apolinarto D. Nazarea
}

Biophysik 7, 85-94 (1971)

\section{Received April 27, 1971}

(i) In (19), the first term in the exponential should read $\sum_{i=1}^{r+2}\left|\psi_{i}\right|$.

(ii) In (24), the right hand side should appear between absolute value signs.

Dr. A.D. Nazarea

Committee on Mathematical Biology

The University of Chicago

939 East Fifty-seventh Street

Chicago, Tllinois 60637, U.S.A. 